\title{
The role of complement immune response on artemisinin-based combination therapy in a population from malaria endemic region of Western Kenya
}

\author{
Christine N. L. Wanjala 1,4†, Elke Bergmann-Leitner ${ }^{2 \dagger}$, Hoseah M. Akala', Geoffrey Odhiambo 1,4, \\ Bernhards R. Ogutu ${ }^{1,5}$, Ben Andagalu', Edwin Kamau ${ }^{1,3^{*}+}$ (ID and Daniel Ochiel ${ }^{1,4+}$
}

\begin{abstract}
Background: Naturally acquired immunity (NAI), which is characterized by protection against overt clinical disease and high parasitaemia, is acquired with age and transmission intensity. The role of NAI on the efficacy of anti-malarial drugs, including artemisinin-based combinations used as the first-line treatment for uncomplicated Plasmodium falciparum, has not been fully demonstrated. This study investigated the role of NAl in response to artemisinin-based combination therapy (ACT), in symptomatic patients living in western Kenya, a high malaria transmission area.

Methods: Sera samples from malaria immune participants $(n=105)$ in a therapeutic efficacy study were assessed for in vitro growth inhibitory activity against the 3D7 strain of $P$. falciparum using a fluorescent-based growth inhibition assay (GIA). Participants' age and parasite clearance parameters were used in the analysis. Pooled sera from malaria naïve participants $(n=6)$ with no Plasmodium infection from malaria non-endemic regions of Kenya was used as negative control.

Results: The key observations of the study were as follows: (1) Sera with intact complement displayed higher GIA activity at lower (1\%) serum dilutions $(p<0.0001)$; (2) there was significant relationship between GIA activity, parasite clearance rate $(p=0.05)$ and slope half-life $(p=0.025)$; and (3) age was a confounding factor when comparing the GIA activity with parasite clearance kinetics.
\end{abstract}

Conclusion: This study demonstrates for the first time there is synergy of complement, pre-existing immunity, and drug treatment in younger patients with symptomatic malaria in a high-transmission area.

Keywords: Malaria antibody, Complement, Malaria immunity, Artemisinin combination therapy, Western Kenya, Malaria holoendemic areas

*Correspondence: edwin.kamau.mil@mail.mil

${ }^{\dagger}$ Christine N. L. Wanjala and Elke Bergmann-Leitner contributed equally to this work

†Edwin Kamau and Daniel Ochiel contributed equally to this work 1 Department of Emerging and Infectious Diseases (DEID), United States Army Medical Research Directorate-Africa (USAMRD-A), Kenya Medical Research Institute (KEMRI)/Walter Reed Project (WRP), Kisumu, Kenya

Full list of author information is available at the end of the article

\section{Background}

People living in malaria endemic areas acquire natural immunity with age, with faster rates of acquisition occurring in high compared to low transmission settings [1]. Both humoral and cell-mediated immune responses are involved in generating effective immunity [2], with individuals who possess greater breadth of immunological responses being at a lower risk of developing overt clinical symptoms [3].

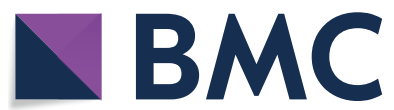

(c) The Author(s) 2020. This article is licensed under a Creative Commons Attribution 4.0 International License, which permits use, sharing, adaptation, distribution and reproduction in any medium or format, as long as you give appropriate credit to the original author(s) and the source, provide a link to the Creative Commons licence, and indicate if changes were made. The images or other third party material in this article are included in the article's Creative Commons licence, unless indicated otherwise in a credit line to the material. If material is not included in the article's Creative Commons licence and your intended use is not permitted by statutory regulation or exceeds the permitted use, you will need to obtain permission directly from the copyright holder. To view a copy of this licence, visit http://creativeco mmons.org/licenses/by/4.0/. The Creative Commons Public Domain Dedication waiver (http://creativecommons.org/publicdomain/ zero/1.0/) applies to the data made available in this article, unless otherwise stated in a credit line to the data. 
Naturally acquired immunity has been shown to influence malaria drug treatment outcomes by enhancing the efficacy of sub-optimal drug regimen and delaying the emergence of drug resistance, including the artemisininbased combinations used as the first-line treatment of Plasmodium falciparum in most malaria endemic countries [4]. Artemisinin-based combination therapy (ACT) is still highly efficacious in sub-Saharan Africa (sSA) [5], but as malaria transmission reduces, and malaria immunity at population level wanes [6], the efficacy of ACT is likely to be impacted. It is, therefore, important to monitor and assess the effect of pre-existing acquired immunity on the efficacy of ACT as part of therapeutic efficacy studies (TESs).

Complement factors have been shown to play a key role in antibody-mediated immunity to malaria in humans [7]. Studies from malaria endemic areas have demonstrated that $P$. falciparum exposure is associated with growth-inhibitory activity in total [8], and merozoite surface protein 1 (MSP-1) or apical membrane antigen 1 (AMA-1)-specific IgG fractions [9, 10]. Growth inhibition assays (GIA) assesses the functional activity of sera to reduce/inhibit red blood cell (RBC) invasion and/or intra-RBC growth of $P$. falciparum in vitro [11]. Using GIA, the present study aimed to assess the role of complement and pre-existing immunity in the response to malaria drug treatment in symptomatic patients living in a malaria high-transmission area of western Kenya.

\section{Methods}

\section{Study site, population and sample collection}

This is a sub-study that analysed samples from a TES conducted in Kombewa district hospital in Kisumu County, western Kenya from June 2013 through November 2014. Detailed clinical study will be reported elsewhere. Briefly, Kisumu County is a malaria holoendemic lake region with intense malaria transmission through-out the year, with annual entomological inoculation rates (EIR) of 31.1 infected bite per year [12]. This was a two-arm, randomized open-label study, where patients presenting with uncomplicated malaria at the Kombewa district hospital between the ages of 6 months to 65 years were recruited (Table 1). Study participants were randomized to receive artemether-lumefantrine (AL) or artesunate-mefloquine (ASMQ) using block randomization schemes with varying block sizes. Venous blood samples were collected at hours $0,4,8,12,18,24$ and then every $6 \mathrm{~h}$ until two consecutive smears became negative. Giemsa-stained films were prepared following World Health Organization (WHO) guidance and read by two independent expert microscopists. The geometric mean of the parasite count per microlitre from each participant at each sampling time point was then calculated. Participants were followed for a total of 42 days. A total of 118 participants were enrolled in the study, 59 from each arm. From these, 105 blood samples from study participants (46 participants who were $<5$ years of age and 59 who were $\geq 5$ years of age) herein regarded as immune sera sample were successfully analysed using the GIA.

Pooled sera from six adult males 18-65 years old, who were $P$. falciparum negative, confirmed by microscopy and polymerase chain reaction (PCR), were used as non-immune control for the GIA experiments. These donors had blood groups $\mathrm{A}, \mathrm{B}$ and $\mathrm{O}$, and haemoglobin level of $\geq 13 \mathrm{~g} / \mathrm{dL}$, living in malaria non-endemic regions (Kericho and Nairobi), with no travel history to malaria endemic areas of Kenya in the last 6 months prior to blood donation. For the maintenance of the parasite culture and performing the GIA assays, red blood cells (RBCs) were obtained from blood group "O" donors, ages between 18 and 50 years, with haemoglobin level of $14-18 \mathrm{~g} / \mathrm{dL}$ for males, and $12-16 \mathrm{~g} / \mathrm{dL}$ for females

Table 1 Demographic information for the study participants

\begin{tabular}{lll}
\hline & AL & ASMQ \\
& $\mathbf{N = 5 9}$ & $\mathbf{N = 5 9}$ \\
\hline Age-mean years (SD) & $6.7(7.1)$ & $8.9(10.1)$ \\
Age-median years (range) & $5(1-50)$ & $6(1-51)$ \\
Sex-female N (\%) & $34(57.6 \%)$ & $35(59.3 \%)$ \\
Mean weight kg (SD) & $24.0(15.7)$ & $25.0(15.1)$ \\
Weight range & $10.6-90.4$ & $11.0-76.6$ \\
Temperature-mean ${ }^{\circ} \mathrm{C}$ (range) & $38.0(36.0-40.1)$ & $37.5(36.1-40.0)$ \\
Mean Hb g/dl (range) & $10.6(7.0-15.1)$ & $10.8(7.2-15.8)$ \\
Asexual parasite density-geometric mean per $\mathrm{LL}(95 \% \mathrm{Cl})$ & $38,759(26,194-57,351)$ & $32,789(21,907-49,078)$ \\
Gametocyte carriage N (\%) & $51(86.4 \%)$ & $52(88.1 \%)$ \\
\hline
\end{tabular}

Malaria episode was defined at a measured temperature of $\geq 37.5^{\circ} \mathrm{C}$ with baseline parasitaemia of $2000-200,000$ asexual parasites/ $\mu \mathrm{L}$. GIA activity was successfully assessed in 105 samples ( $52 \mathrm{AL}$ arm and $53 \mathrm{ASMQ}$ arm), where 46 ( 23 females) were $<5$ years old, and 59 ( 38 females) were $\geq 5$ years old 
living in a malaria non-endemic area (Kericho and Nairobi) with no travel history to malaria endemic areas in the last 6 months prior to donating blood. After collection, the blood was kept in cool boxes containing $2-8{ }^{\circ} \mathrm{C}$ ice parks with portable thermometers, which were safely transported to the central lab by courier service provider under monitored cold chain within $24 \mathrm{~h}$. The cold chain, and sample integrity including absence of lysis and leakage was verified by the receiving technician and documented in the laboratory record book prior to processing as previously described [13]. Briefly, in $15 \mathrm{~mL}$ centrifuge tubes, $7 \mathrm{~mL}$ aliquots of the whole blood were added to $7 \mathrm{~mL}$ wash medium and then centrifuged at $800 \mathrm{~g}$ for $10 \mathrm{~min}$ where most white blood cells (WBCs) in buffy coat were gently aspirated, followed by the entire supernatant, leaving the packed RBCs. The process was repeated three-time to remove all the remaining WBCs. The cells were then suspended in equivalent wash medium at $50 \%$ haematocrit (packed cells/wash medium $\mathrm{v} / \mathrm{v})$, then stored at $2-8{ }^{\circ} \mathrm{C}$.

\section{Culture media}

Culture medium used to maintain $P$. falciparum in vitro (Life technologies, Carlsbad, CA) was prepared as previously described [14]. Briefly, basic media comprised of 10.4 g RPMI powder (Invitrogen, Inc., Carlsbad, California, USA) combined with $2 \mathrm{~g}$ of glucose (Sigma Inc., St Louis, Missouri, USA) and 5.95 g HEPES (Sigma, USA) dissolved to homogeneity in 1 litre of de-ionized water and sterilized with a $0.2 \mu \mathrm{M}$ filter. RPMI 1640 tissue culture media (TCM), for all parasite culture and drug dilutions, consisted of RPMI 1640 basic media with 0.5\% Albumax II (Gibco, Grand Island, NY), 3.2\% (vol/ vol) sodium bicarbonate (Thermo Fisher Scientific Inc., Waltham, Massachusetts, USA) and $4 \mu \mathrm{g} / \mathrm{mL}$ hypoxanthine (Sigma Inc., St Louis, Missouri, USA). Complete RPMI 1640 media was stored at $2-8{ }^{\circ} \mathrm{C}$. Serum free media consisted of $1.0 \mathrm{~mL}$ of $1.45 \mathrm{mM}$ sterile hypoxanthine to $43.4 \mathrm{~mL}$ of RPMI basic medium, $1.6 \mathrm{~mL}$ of sterile sodium bicarbonate (Thermo Fisher Scientific Inc., Waltham, Massachusetts, USA), $7.5 \%$ and sterilized with $0.2 \mu \mathrm{M}$ filter then put in $2-8{ }^{\circ} \mathrm{C} .10 \%$ complete media for Control was prepared by adding $5 \mathrm{~mL}$ of serum to $43.4 \mathrm{~mL}$ of RPMI basic medium, $1.0 \mathrm{~mL}$ of $1.45 \mathrm{mM}$ sterile hypoxanthine, $1.6 \mathrm{~mL}$ of sterile sodium bicarbonate, $7.5 \%$ then sterilized with $0.8 \mu \mathrm{M}, 0.45 \mu \mathrm{M}, 0.2 \mu \mathrm{M}$ filters and put at $2-8{ }^{\circ} \mathrm{C}$.

\section{Plasmodium falciparum culture}

Plasmodium falciparum 3D7 strain, obtained through Biodefense and Emerging Infections Research Resources Repository (BEI Resources, NIAID, NIH) was maintained in continuous culture as previously described
[13]. Briefly, P. falciparum-3D7 were suspended in $5 \mathrm{~mL}$ of complete media with serum (CMS) at $6 \%$ haematocrit in tissue culture flasks (Corning Glass Works, Corning, NY). The flasks were flushed with a gas mixture consisting of $5 \%$ oxygen, $5 \%$ carbon (IV) oxide and $90 \%$ nitrogen (Air Products Corp., Allentown, PA), sealed, and incubated at $37^{\circ} \mathrm{C}$. The medium was changed daily, and fresh RBCs added when required. Parasite growth was monitored microscopically by counting Giemsa-stained thin blood smears. When parasitaemia exceeded 3\%, ring-stage parasites were synchronized by sorbitol lysis (5\% D-sorbitol (Sigma, St. Louis, MO) as follows: Parasites were mixed and transferred into a $15 \mathrm{~mL}$ centrifuge tube and centrifuged at $800 \mathrm{~g}$ for $10 \mathrm{~min}$. After removing the supernatant, $5 \% \mathrm{D}$-sorbitol pre-warmed to $37^{\circ} \mathrm{C}$ was added to the RBC pellet, incubated for $10 \mathrm{~min}$ at $37^{\circ} \mathrm{C}$, vortexed for $1 \mathrm{~min}$ and re-centrifuged at $800 \mathrm{~g}$ for $10 \mathrm{~min}$. After aspirating the supernatant and repeating the process twice using $\mathrm{TCM}, \geq 90 \%$ ring forms was achieved.

\section{Serum preparation}

Serum was obtained from blood samples as previously described [15] with minor modifications. Briefly, whole blood collected in plain (anticoagulant free) blood bags from each study participant was stored at $2-8{ }^{\circ} \mathrm{C}$ overnight to allow settling of the serum and cells portions. Serum portion was transferred into $50 \mathrm{~mL}$ centrifuge tubes, and centrifuged at $800 \mathrm{~g}$ for $10 \mathrm{~min}$. The supernatant was transferred into $50 \mathrm{~mL}$ centrifuge tube to remove all cell components. This step was repeated three times, and the serum was stored at -65 to $-80{ }^{\circ} \mathrm{C}$ until further use. The sera from the six male adults (non-immune) was pooled together forming approximately $2000 \mathrm{~mL}$, which was used as negative control for subsequent experiments. Serum from each of the immune or non-immune pooled serum was divided into two equal portions. One portion was heat inactivated at $56{ }^{\circ} \mathrm{C}$ for $30 \mathrm{~min}$ in a water bath, as previously described [7]. Experiments were carried out in 1 or $10 \%$ sera, prepared as previously described [7]. Briefly, 10\% immune or non-immune CMS was prepared by adding $0.5 \mathrm{~mL}$ participant's serum to $4.5 \mathrm{~mL}$ serum free media. To prepare $1 \%$ immune or non-immune CMS, $0.5 \mathrm{~mL}$ of $10 \%$ immune/non-immune CMS was added to $4.5 \mathrm{~mL}$ serum free media, making a tenfold dilution. This was done for heat-inactivated and non-heat inactivated sera.

\section{Growth inhibition assay (GIA)}

In vitro anti-plasmodial susceptibility assay was performed as previously described [14] with some modifications. Briefly, tenfold dilution in TCM was done for immune serum, non-immune serum, and negative control wells. Parasitaemia in the GIA assays of continuous 
culture that were greater than $3 \%$ were lowered to $1 \%$, and adjusted to final 1-2\% hematocrit. A ratio of 1:10 serum dilution in $100 \mu \mathrm{L}$ final volume was dispensed on Nalgene Nunc, 96 flat-bottom well cell cultures sterile with lid microlitre plates (Magna, Leicestershire, UK), and $10 \mu \mathrm{L}$ of 3D7 parasite was added in each well then incubate at $37^{\circ} \mathrm{C}$ for $72 \mathrm{~h}$ in modular reservoirs, gassed with $90 \%$ nitrogen, $5 \%$ carbon dioxide and $5 \%$ oxygen. Parasite growth was evaluated using SYBR Green I fluorescence assay as follows: $4 \mu \mathrm{L}$ of 10X SYBR Green I dye was added to $2 \mathrm{~mL}$ of malaria SYBR Green I lysis buffer [20 mM Tris (pH 7.5), 5 mM EDTA, 0.16\% (wt/vol) saponin, and $1.6 \%$ (vol/vol) Triton X-100], and $100 \mu \mathrm{L}$ of this mixture was transferred to each well. The plates were stored in the dark at ambient temperature for $24 \mathrm{~h}$ [16]. The plates were then examined for relative fluorescence units (RFUs) per well using a fluorescence plate reader (Tecan $^{\text {TM }}$ Morrisville, North Carolina, United States). Parasite replication was quantified for each serum sample (immune/pooled non-immune sera) and expressed as the mean percentage growth inhibition by: counts (usually in at least $2000 \mathrm{RBCs}$ ). The readouts of counts per either WBCs or RBCs were converted to parasite densities at time points $0,4,8,12,18,24,30,36,42$, and $48 \mathrm{~h}$, then continued at least every $24 \mathrm{~h}$ until clearance depicted by until two subsequent negative malaria blood slides. A malaria blood film was considered negative if no parasite observed after scanning 200 high power fields (since a high quality HPF contains about 20 WBCs, this represents approximately $4000 \mathrm{WBCs}$ ). Data on parasite density was converted to csv file format and uploaded into the WWARN parasite clearance estimator.

Data was downloaded from the PCE and the following parameters were estimated: parasite clearance half-life, parasite clearance rate constant $(\mathrm{K} / \mathrm{h})$, and the estimated time to reduce parasitaemia by $50 \%$ (PC50), $90 \%$ (PC90), 95\% (PC95), and 99\% (PC99). Log transformed parasite density was plotted against time in hours to generate slope half-life $\left(\mathrm{T}_{1 / 2}\right)$ which is defined as the time needed for parasitaemia to be reduced by half [18]. This constant is independent of starting value of parasitaemia. The slope half-life was calculated as follows: $\mathrm{T}_{1 / 2}=\log _{\mathrm{e}}$

$$
\text { Percentage growth inhibition }=\frac{\text { average RFUs in growth medium }- \text { average RFUs inpatients serum/pooled serum }}{\text { Average RFU in growth medium }} \times 100 \%
$$

Optimization was done to validate the assay and control reference ranges were established upon which the assay performance was monitored using anti-malarial drugs dihydroartemisinin (DHA) and lumefantrine (LU) that have known $\mathrm{IC}_{50}$ for the reference parasite strain. The drugs DHA and LU were used as positive control and tissue culture media (10\% CMS) was used as negative control. All experiments were conducted in triplicate.

\section{Parasite clearance rates calculation}

The statistical models used to estimate the parasite clearance measures and lag phase duration were fitted using the Parasite Clearance Estimator (PCE) tool developed by Worldwide Antimalarial Resistance Network (WWARN) [17]. Briefly, thick and thin smears of malaria blood slides were generated examined under light microscope at $100 \times$ magnification for presence of malaria parasites as part of monitoring treatment outcome. From the initial scan through slides with parasite counts/WBC count ratio less than 2 in thick smears were regarded as low density infection and reading done in this smear. The parasite density in this low density smears were estimated as the number of parasites, the asexual forms only, counted against the number of white blood cells (usually 200 for low density or 500 for extra low density with less than 10 parasites pre $200 \mathrm{WBCs})$. Slides with parasite counts/WBC count ratio exceeding two were counted in thin smear as infected RBC counts/total number of RBC
(2) $/ \mathrm{K}=0.692 / \mathrm{K}$, where $\mathrm{K}$ is the clearance rate constant. The clearance rate $\mathrm{K}$ represents the rate of parasite clearance after start of drug treatment.

\section{Statistical analysis}

Data was analysed using GraphPad Prism version 5.03 (GraphPad software, Inc., San Diego, CA) and Minitab, Version 17 (Minitab Inc., State College, PA). Normality of the data was confirmed using Shapiro-Wilk test. Data are presented as the median with interquartile range ([IQR] 25th and 75th percentiles). Statistical difference between groups was determined using $t$ test and Wilcoxon matched-pairs signed rank test. Correlation between groups was assessed using Pearson correlation coefficient test. Differences with a $p$-value less than 0.05 were considered statistically significant.

\section{Results}

\section{Growth inhibitory activity}

The in vitro growth inhibition of P. falciparum in serum from the 105 immune study participants and nonimmune were compared using Wilcoxon matched pair signed rank test. The percentage growth inhibition of $P$. falciparum at 10 and $1 \%$ serum concentration from the study participants was significantly higher than for the non-immune controls $(p<0.0001)$ (Fig. 1), indicating parasite growth inhibition was due to the immune status. There was no statistically significant difference in 


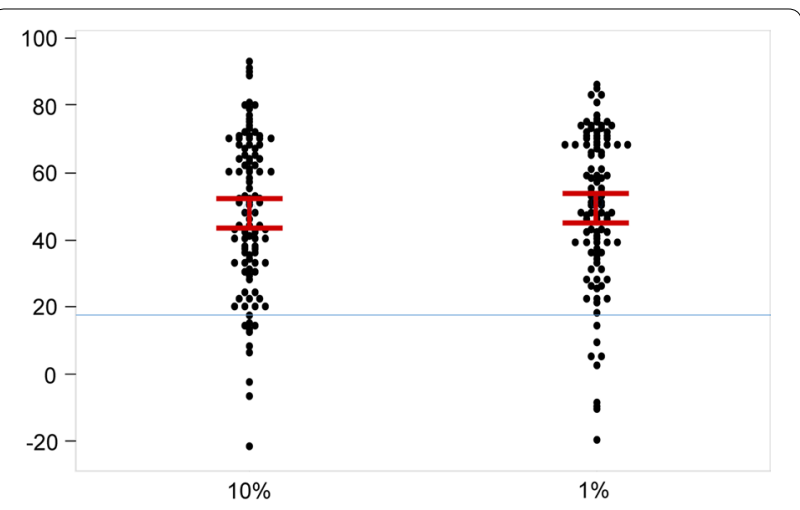

Fig. 1 Anti-parasite activity in sera from study participants reaches saturation at a low testing concentration. Individual data plot represents in vitro growth inhibition of $P$. falciparum parasites (3D7) in the presence of $10 \%$ or $1 \%(\mathrm{v} / \mathrm{v})$ serum concentration from immune patients. Circles indicate results for each study participant $(n=105)$. A serum pool consistent of six non-immune volunteers (indicated by blue line) was tested to determine background activity of the GIA assay. Median and 95\% confidence interval are indicated for each experimental conditions

percentage growth inhibition for heat inactivated $(+\mathrm{HA})$ serum compared to non-heat inactivated $(-\mathrm{HA})$ serum at $10 \%$ serum concentration $(p=0.18)$. Conversely, the percentage growth inhibition was significantly higher for - HA serum than + HA serum at $1 \%$ serum concentration $(p=0.009)$ (Fig. 2). The results revealed the role of complement when the assay was performed at $1 \%$ serum concentrations where antibodies are at limiting concentrations.

\section{Age and GIA activity}

To determine whether age or parasitaemia were confounding factors in GIA, the GIA data were stratified based on individuals younger than 5 years $(<5$ years) or 5 years and older ( $\geq 5$ years). There was no age-dependence of GIA activity nor significant correlation between
GIA activity and parasite density $\left(\mathrm{R}^{2}=0.03, \mathrm{p}=0.95\right.$ Pearson correlation coefficient) (Fig. 3).

\section{Impact of pre-existing immunity, GIA and treatment outcome}

The main question of the present study was whether pre-existing immunity had an impact on the parasitological outcome after drug treatment and the kinetic of the response. The mean $\mathrm{T}_{1 / 2}$ for both study arms combined was $2.38 \mathrm{~h}$ (95\% confidence interval [CI], 2.23-2.52), the median was $2.40 \mathrm{~h}$ (interquartile range [IQR], 1.95-2.80), and the range was $0.97-4.22 \mathrm{~h}$. The cutoff values for stratifying into the two different groups have previously been described $[19,20]$. Correlations between drug treatment outcome as determined by parasite clearance parameters (slope half-life $\left[\mathrm{T}_{1 / 2}\right]$ and clearance rate $[\mathrm{K}]$ ) and pre-existing GIA activity in sera were assessed (Table 2). The main observation when performing the statistical analyses was that stratifying the data based on the kinetic of the drug response revealed two factors, complement and age were associated with a faster parasite clearance and slope halflife. Non-heat inactivated sera from study participants younger than 5 years showed a significant negative correlation between GIA activity and slope half-life $\left(R^{2}=0.698, p=0.025\right.$ Pearson correlation $)$ and a significant positive correlation between GIA activity and parasite clearance $\left(R^{2}=0.604, p=0.05\right.$ Pearson correlation). These correlations are lost when sera were heat-inactivated, clearly demonstrating the role of complement in clearing the parasite under drug treatment.

\section{Discussion}

The present study utilized samples from a TES study with a comprehensive immunological profile [20] and parasitological characterization. To complete the immuneparasitological profile, the functional activity of sera
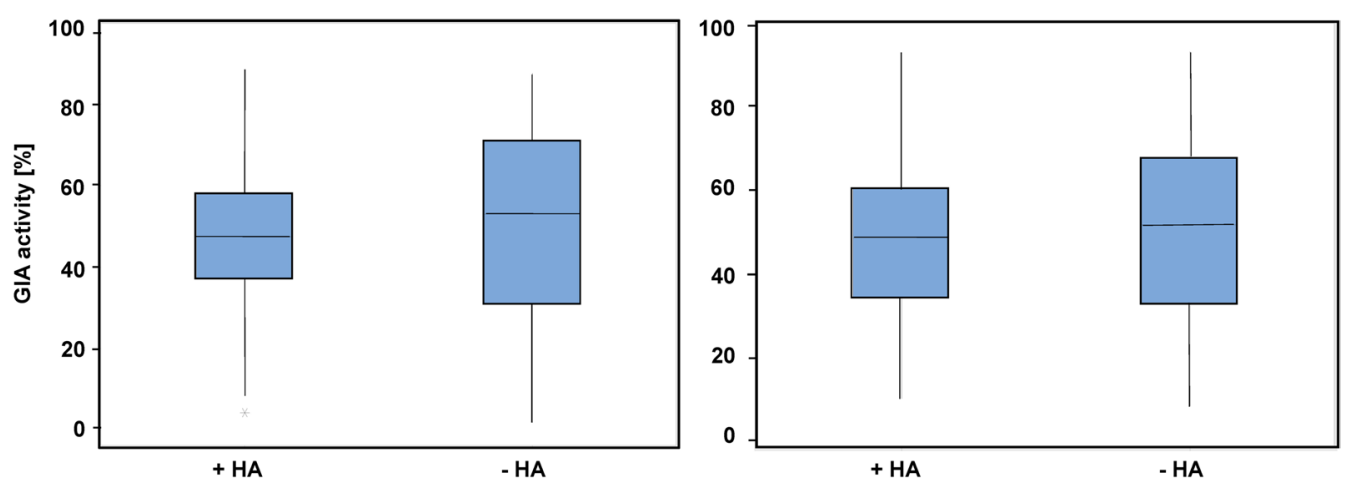

Fig. 2 The contribution of complement to anti-parasite activity in sera is revealed at lower concentrations. Boxplot comparing GIA activity of Sera tested at $1 \%$ (left panel) $(n=105)$ and $10 \%$ (right panel) $n=105)$ with $(+\mathrm{HA})$ and without $(-\mathrm{HA})$ complement inactivation 


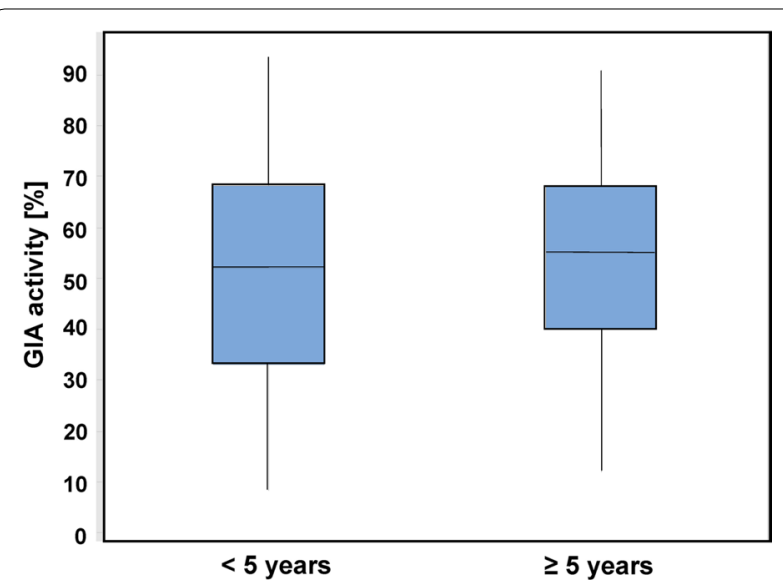

Fig. 3 Age is not a confounding factor in the entire patient population. Boxplot showing impact of age $<5$ years $(n=46)$ and $\geq 5$ years $(n=59)$ on GIA in sera from symptomatic patients

collected prior to drug treatment was assessed in a sensitive GIA assay [14]. To determine the contribution of innate factors such as complement, sera were tested with and without heat-inactivation. The initial analysis showed that the contribution of complement to the anti-parasite activity was only notable at low serum concentrations, where anti-malarial antibodies are likely under limiting concentrations. This confirms previous reports demonstrating the role of complement in GIA activity [7, 20].

The next step was to determine the impact of age on the GIA activity. Contrarily to a previous study [21], an age-dependent response in the functional activity was not displayed by the sera. This contradiction is likely because in the current study, population is comprised of participants that presented with malaria symptoms while other studies investigated the role of age in asymptomatic populations.
The key observation of this study was made when the data were stratified based on the drug kinetic response of the study participants [20]. This classification revealed that the parasitological response (i.e., parasite clearance rate and slope half-life) to drug was linked to GIA activity in non-heat-inactivated sera in patients under the age of five (Table 2). This finding suggests that the role of complement varies depending on the age of the study participant, corroborating previous studies that have demonstrated the importance of age in immune acquisition [22-24]. Previous assessment of the serological antibody profile did not find differences between the age groups [20] and, therefore, findings in this study points towards a greater role of innate factors in younger patients. The need for complement and complement fixing antibodies has been reported to be crucial for the protection against malaria clinical disease [7], supporting observation in this study that heat-inactivated serum has lower GIA activity. It does not preclude that there may be differences in the levels of malaria-specific IgM which has not been assessed. This is the main antibody isotype fixing complement and there may be differences in the distribution of malaria-specific IgM and IgG in the different age groups.

\section{Conclusion}

In conclusion, the present study reveals differential relationships between adaptive immunity, innate immunity (mainly the role of complement), and response to drug treatment as function of age of the symptomatic study participants. Anti-parasitic activity (GIA) significantly correlated with $T_{1 / 2}$ and $K$ only in sera of younger symptomatic patients. This effect is dependent of intact (nonheat inactivated serum) indicating the importance of innate factors such as complement. These findings provide insight into improvement in effective use of ACT

Table 2 Correlation between parasitological response to drugs and pre-existing GIA activity

\begin{tabular}{|c|c|c|c|c|c|c|}
\hline \multirow{2}{*}{$\begin{array}{l}\text { Clearance kinetic } \\
\text { a }\end{array}$} & \multirow[t]{2}{*}{ Age group } & \multirow[t]{2}{*}{ n subjects } & \multicolumn{2}{|l|}{$T_{1 / 2} v G_{I A}^{b}$} & \multicolumn{2}{|l|}{ K vs GIAb } \\
\hline & & & $-H A^{c}$ & $+H A^{c}$ & $-\mathrm{HA}$ & $+\mathrm{HA}$ \\
\hline \multirow[t]{2}{*}{$<2.02$} & $<5$ years & 9 & $\begin{array}{l}R^{2}=-0.698 \\
p=0.025^{*}\end{array}$ & $\begin{array}{l}R^{2}=-0.413 \\
P=0.207\end{array}$ & $\begin{array}{l}R^{2}=0.604 \\
p=0.05^{*}\end{array}$ & $\begin{array}{l}R^{2}=0.302 \\
p=0.367\end{array}$ \\
\hline & $\geq 5$ years & 16 & $\begin{array}{l}R^{2}=-0.181 \\
p=0.518\end{array}$ & $\begin{array}{l}R^{2}=-0.042 \\
p=0.886\end{array}$ & $\begin{array}{l}R^{2}=-0.03 \\
p=0.915\end{array}$ & $\begin{array}{l}R^{2}=-0.043 \\
p=0.878\end{array}$ \\
\hline \multirow[t]{2}{*}{$>2.02$} & $<5$ years & 37 & $\begin{array}{l}R^{2}=0.21 \\
p=0.304\end{array}$ & $\begin{array}{l}R^{2}=0.193 \\
p=0.335\end{array}$ & $\begin{array}{l}R^{2}=-0.217 \\
p=0.208\end{array}$ & $\begin{array}{l}R^{2}=-0.158 \\
P=0.432\end{array}$ \\
\hline & $\geq 5$ years & 43 & $\begin{array}{l}R^{2}=-0.017 \\
p=0.923\end{array}$ & $\begin{array}{l}R^{2}=-0.221 \\
P=0.217\end{array}$ & $\begin{array}{l}R^{2}=0.037 \\
p=0.837\end{array}$ & $\begin{array}{l}R^{2}=0.266 \\
P=0.2\end{array}$ \\
\hline
\end{tabular}

a Stratification of study participants based on Slope half-life $\mathrm{T} 1 / 2{ }^{17}$ measured in hours

b Correlation expressed as Pearson correlation coefficient $\left(R^{2}\right)$; asterisk indicates statistical significance $(p \leq 0.05)$

c $\mathrm{GIA}$ activity assessed in sera without $(-\mathrm{HA})$ or with heat-inactivation $(+\mathrm{HA})$ 


\section{(dose adjustments) in relation to age in malaria endemic areas.}

\begin{abstract}
Abbreviations
ACT: Artemisinin-based combination therapy; AL: Artemether-lumefantrine: AMA-1: Apical membrane antigen 1; ASMQ: Artesunate mefloquine; BEI: Biodefense and Emerging Infections Research Resources Repository; CMS: Complete media with serum; CNHR: Consortium for National Health Research; DEID: Department of Emerging and Infectious Diseases; DHA: Dihydroartemisinin; EIR: Entomological Inoculation Rates; GIA: Growth Inhibition Assay; -HA: Non-heat inactivated; +HA: Heat inactivated; K: Clearance rate; K/hour: Parasite clearance rate constant; KEMRI: Kenya Medical Research Institute; LU: Lumefantrine; MSP-1: Merozoite surface protein 1; NAl: Naturally acquired immunity; PCE: Parasite clearance estimator; PCR: Polymerase chain reaction; RBC: Red blood cell; RFUs: Relative fluorescence units; SSA: sub-Saharan Africa; TCM: Tissue culture media; TESs: Therapeutic efficacy studies; $T_{1 / 2}$ : Slope half-life; USAMRD-A: United States Army Medical Research Directorate-Africa; WBCs: White blood cells; WHO: World Health Organization; WRAIR: Walter Reed Army Institute of Research; WRP: Walter Reed Project.
\end{abstract}

\section{Acknowledgements}

The authors would like to acknowledge the participants in Kombewa District Hospital, the research staff, Kenya Medical Research Institute and United States Medical Research Directorate-Africa for their support. We would like to thank all the colleagues in the Malaria Drug Resistance laboratory for their technical and moral support. We would also thank the Director of KEMRI for permission to publish this work

\section{Disclaimer}

Material has been reviewed by the Walter Reed Army Institute of Research. There is no objection to its presentation and/or publication. The opinions or assertions contained herein are the private views of the author, and are not to be construed as official, or as reflecting true views of the Department of the Army or the Department of Defense. The investigators have adhered to the policies for protection of human subjects as prescribed in AR 70-25.

\section{Authors' contributions}

$\mathrm{DO}, \mathrm{BO}$, EK provided funding. BA provided clinical study samples, conducted clinical data analysis. CW, DO and EK designed the study protocol. CW performed laboratory assays. HA supervised and provided assays execution guidance. CW, EBL, EK, DO, GO performed data analysis and interpretation. $C W, E B L, E K$ wrote manuscript. DO, EK, EBL, BO, BA revised, and reviewed the final manuscript draft. CW, EBL, HA, GO, BO, BA, EK approved final manuscript.

\section{Funding}

This work was supported by the Armed Forces Health Surveillance CenterDepartment of Defense Global Emerging Infections System and by the Consortium for National Health Research (CNHR) grant \# RCDG-2012-032/Alternative-2014 to Dr. Daniel Ochiel. The funders did not participate in the design of the study and collection, analysis, and interpretation of data and in writing the manuscript through the co-authors who work for the organizations.

\section{Availability of data and materials}

All data generated or analysed during this study are included in this published article.

\section{Ethics approval and consent to participate}

The study was approved by the scientific and ethics review boards of the Kenya Medical Research Institute, Nairobi Kenya (KEMRI; approved protocol \# 2518) and the Institutional Review Board of the Walter Reed Army Institute of Research, Silver Spring, MD (WRAIR; approved protocol \#1935). This study was also registered at clinicaltrials.gov (NCT01976780). All participants and/or their legal guardians gave a voluntary written informed consent before any study procedures commenced.

\section{Consent for publication}

Not applicable. No personal identifiable data was used in the study. All authors have provided consent to publish the findings in this study.

\section{Competing interests}

The authors declare that they have no competing interests.

\section{Author details}

${ }^{1}$ Department of Emerging and Infectious Diseases (DEID), United States Army Medical Research Directorate-Africa (USAMRD-A), Kenya Medical Research Institute (KEMRI)/Walter Reed Project (WRP), Kisumu, Kenya. ${ }^{2}$ Malaria Biologics Branch, Walter Reed Army Institute of Research, Silver Spring, MD, USA. ${ }^{3}$ U.S. Military HIV Research Program, Walter Reed Army Institute of Research, Silver Spring, MD, USA. ${ }^{4}$ School of Physical and Biological Sciences Zoology Department, Maseno University, Maseno, Kenya. ${ }^{5}$ KEMRI, Nairobi, Kenya.

Received: 9 December 2019 Accepted: 18 April 2020

Published online: 29 April 2020

\section{References}

1. Fowkes FJ, Boeuf P, Beeson JG. Immunity to malaria in an era of declining malaria transmission. Parasitology. 2016;143:139-53.

2. Beeson JG, Osier FH, Engwerda CR. Recent insights into humoral and cellular immune responses against malaria. Trends Parasitol. 2008;4:578-84.

3. Osier FH, Fegan G, Polley SD, Murungi L, Verra F, Tetteh KK, et al. Breadth and magnitude of antibody responses to multiple Plasmodium falciparum merozoite antigens are associated with protection from clinical malaria. Infect Immun. 2008;76:2240-8.

4. Ataide R, Ashley EA, Powell R, Chan JA, Malloy MJ, O'Flaherty K, et al. Host immunity to Plasmodium falciparum and the assessment of emerging artemisinin resistance in a multinational cohort. Proc Natl Acad Sci USA 2017;114:3515-20.

5. WHO. World Malaria Report 2017. Geneva: World Health Organization; 2017

6. Mugyenyi CK, Elliott SR, Yap XZ, Feng G, Boeuf P, Fegan G, et al. Declining malaria transmission differentially impacts the maintenance of humoral immunity to Plasmodium falciparum in children. J Infect Dis. 2017:216:887-98

7. Boyle MJ, Reiling L, Feng G, Langer C, Osier FH, Aspeling-Jones $\mathrm{H}$, et al. Human antibodies fix complement to inhibit Plasmodium falciparum invasion of erythrocytes and are associated with protection against malaria. Immunity. 2015;42:580-90.

8. McCallum FJ, Persson KE, Mugyenyi CK, Fowkes FJ, Simpson JA, Richards JS, et al. Acquisition of growth-inhibitory antibodies against blood-stage Plasmodium falciparum. PLoS One. 2008;3:e3571

9. Murhandarwati EE, Wang L, Black CG, Nhan DH, Richie TL, Coppel RL. Inhibitory antibodies specific for the 19-kilodalton fragment of merozoite surface protein 1 do not correlate with delayed appearance of infection with Plasmodium falciparum in semi-immune individuals in Vietnam. Infect Immun. 2009;77:4510-7.

10. Hodder AN, Crewther PE, Anders RF. Specificity of the protective antibody response to apical membrane antigen 1. Infect Immun. 2001:69:3286-94.

11. Crompton PD, Miura K, Traore B, Kayentao K, Ongoiba A, Weiss G, et al. In vitro growth-inhibitory activity and malaria risk in a cohort study in mali. Infect Immun. 2010;78:737-45.

12. Omukunda E, Githeko A, Ndong'a MF, Mushinzimana E, Atieli H, Wamae P. Malaria vector population dynamics in highland and lowland regions of western Kenya. J Vector Borne Dis. 2013;50:85-92.

13. Trager W, Jensen JB. Human malaria parasites in continuous culture Science. 1976;193:673-5.

14. Johnson JD, Dennull RA, Gerena L, Lopez-Sanchez M, Roncal NE, Waters NC. Assessment and continued validation of the malaria SYBR green I-based fluorescence assay for use in malaria drug screening. Antimicrob Agents Chemother. 2007:51:1926-33.

15. Persson KE, McCallum FJ, Reiling L, Lister NA, Stubbs J, Cowman AF, et al. Variation in use of erythrocyte invasion pathways by Plasmodium falciparum mediates evasion of human inhibitory antibodies. J Clin Invest. 2008;118:342-51.

16. Cheruiyot AC, Auschwitz JM, Lee PJ, Yeda RA, Okello CO, Leed SE, et al Assessment of the Worldwide Antimalarial Resistance Network standardized procedure for in vitro malaria drug sensitivity testing using SYBR Green assay for field samples with various initial parasitemia levels. Antimicrob Agents Chemother. 2016;60:2417-24. 
17. Parasite Clearance Estimator. https://www.wwarn.org/parasite-clearanceestimator-pce. Accessed 01 Aug 2019.

18. Flegg JA, Guerin PJ, White NJ, Stepniewska K. Standardizing the measurement of parasite clearance in falciparum malaria: the parasite clearance estimator. Malar J. 2011;10:339.

19. Chebon $L$, Ngalah BS, Ingasia LA, Juma DW, Muiruri P, Cheruiyot J, et al. Genetically determined response to artemisinin treatment in Western Kenyan Plasmodium falciparum parasites. PLOS ONE. 2016;11:e0162524.

20. Odhiambo G, Bergmann-Leitner E, Maraka M, Wanjala CNL, Duncan E, Waitumbi J, et al. Correlation between malaria-specific antibody profiles and responses to artemisinin combination therapy for treatment of uncomplicated malaria in western Kenya. J Infect Dis. 2019;219:1969-79.

21. Dent AE, Bergmann-Leitner ES, Wilson DW, Tisch DJ, Kimmel R, Vulule J, et al. Antibody-mediated growth inhibition of Plasmodium falciparum: relationship to age and protection from parasitemia in Kenyan children and adults. PLoS ONE. 2008;3:e3557.

22. Djimde AA, Doumbo OK, Traore O, Guindo AB, Kayentao K, Diourte Y, et al Clearance of drug-resistant parasites as a model for protective immunity in Plasmodium falciparum malaria. Am J Trop Med Hyg. 2003;69:558-63.

23. Doolan DL, Dobano C, Baird JK. Acquired immunity to malaria. Clin Microbiol Rev. 2009;22:13-36.

24. Marsh K, Kinyanjui S. Immune effector mechanisms in malaria. Parasite Immunol. 2006;28:51-60

\section{Publisher's Note}

Springer Nature remains neutral with regard to jurisdictional claims in published maps and institutional affiliations.
Ready to submit your research? Choose BMC and benefit from:

- fast, convenient online submission

- thorough peer review by experienced researchers in your field

- rapid publication on acceptance

- support for research data, including large and complex data types

- gold Open Access which fosters wider collaboration and increased citations

- maximum visibility for your research: over $100 \mathrm{M}$ website views per year

At BMC, research is always in progress.

Learn more biomedcentral.com/submissions 